\title{
Systemische Epidemien
}

Ziel ist es, die Wirksamkeit eines Epidemiesystems und die Möglichkeit der Vorausschau mit statistisch-probabilistischen Methoden zu erkennen. Hierzu müssen die systemischen Bedingungen geklärt werden. 